


\title{
POTENSI PENERAPAN TEKNOLOGI BERSIH DAN MINIMASI LIMBAH PADA INDUSTRI KOPI PURNAMA
}

\author{
Athalia Meifira $^{1}$, Nurul Fadilah ${ }^{1}$, Tiara Insanul Oktariana ${ }^{1}$, \\ Dian Rahayu Jati ${ }^{1}$, dan Isna Apriani ${ }^{1}$ \\ ${ }^{1}$ Jurusan Teknik Lingkungan, Fakultas Teknik Universitas Tanjungpura \\ Email: athmeifira@gmail.com
}

\begin{abstract}
The application of clean production to the Purnama Coffee industry can reduce the negative impact on the environment. This study aims to analyze the coffee industry and consider the potential for implementing clean production by the industry. This research was conducted using the Field Research method (field research). The data collected is then processed into data used for the application of clean production. The results of this study indicate that the implementation of clean production can minimize the impact on the environment. The benefit of clean production for the environment is a reduction in solid waste in the industry. This step in implementing clean production will reduce the impact on the environment towards a more environmentally friendly coffee industry.
\end{abstract}

Keywords: clean production, coffee waste, industry coffee

\begin{abstract}
Abstrak
Penerapan produksi bersih pada industri Kopi Purnama dapat mengurangi dampak negatif terhadap lingkungan. Penelitian ini bertujuan untuk melakukan analisis pada industri kopi serta menganalisis potensi penerapan produksi bersih yang sesuai dengan industri tersebut. Penelitian ini dilakukan dengan metode Field Research (penelitian lapangan). Data-data tersebut dikumpulkan kemudian dianalisis untuk dijadikan potensi penerapan produksi bersih. Hal-hal yang bisa dilakukan dalam penerapan produksi bersih pada industri kopi purnama, antara lain : pembuatan pupuk bokashi dari sekam kulit kopi, sehingga diharapkan ada pengurangan timbulan limbah padat di industri tersebut, sehingga menjadi industri kopi yang lebih ramah lingkungan.
\end{abstract}

Kata Kunci: industri kopi, limbah kopi, produksi bersih 


\section{PENDAHULUAN}

Kopi banyak memberikan manfaat di setiap bagian masyarakat Indonesia. Selain memiliki fungsi ekonomi, kopi juga memiliki fungsi sosial. Adapun jenis kopi yang banyak dikembangkan oleh masyarakat di Indonesia adalah kopi robusta. Menurut data Badan Pusat Statistik (BPS) perkebunan pada tahun 2008, sekitar 86,38\% tanaman kopi yang ditanam di Indonesia adalah jenis robusta dimana $96,33 \%$ nya berasal dari perkebunan rakyat. Mutu kopi robusta yang dihasilkan petani umumnya masih rendah karena pengolahan pasca panen masih menghasilkan kopi asalan, yaitu biji kopi yang dihasilkan dengan metode dan fasilitas sangat sederhana, kadar air relatif tinggi dan masih tercampur dengan bahan-bahan lain dalam jumlah relatif banyak (BPS 2008).

Teknik pengolahan yang dilakukan juga masih sederhana sehingga limbah yang ditimbulkan tidak begitu signifikan, hanya saja polusi dari penggorengan kopi dinilai cukup berdampak. Salah satu contoh dampak yang ditimbulkannya yaitu bau yang busuk, dan bau tersebut muncul dengan cepat. Hal ini disebabkan oleh kulit kopi memiliki kadar air yang tinggi, yaitu sekitar $75-80 \%$.

Kopi Purnama yang telah berdiri selama 30 tahun ini merupakan salah satu produsen yang melakukan pengolahan kopi sendiri, tetapi pabrik ini hanya mengolah biji kopi mentah menjadi bubuk kopi. Sedangkan biji kopi mentah biasanya dipesan perkebunan kopi yang berada di Punggur dan Sumatera. Proses pengolahan kopi dari biji kopi mentah menjadi bubuk kopi menghasilkan limbah padat yang akan menimbulkan permasalahan lingkungan. Limbah padat dan cair yang dihasilkan dari tahapan pengolahan kopi basah sangat banyak. Upaya pemanfaatan limbah pengolahan kopi baik dalam bentuk padat maupun cair menjadi produk yang memiliki nilai ekonomi lebih tinggi perlu dilakukan.

\section{METODE PENELITIAN}

Penelitian ini dilakukan pada tanggal 26 September 2020 di industri kopi Jalan Purnama, Kota Pontianak, Kalimantan Barat. Penelitian ini dilakukan dengan metode field research (penelitian lapangan), merupakan metode pengumpulan data yang dilakukan di lapangan. Tahapan penelitian ini terdiri dari penentuan industri, kemudian perizinan, selanjutnya pengumpulan data, analisis data, dan terakhir pemilihan konsep produksi bersih.

\section{HASIL DAN PEMBAHASAN \\ Proses Pengolahan Kopi}

Biji kopi yang diolah di industri kopi purnama adalah biji yang berasal dari perkebunan kopi di Punggur, Segedong, Ambawang, dan Jakarta. Tahap pertama pengolahan yaitu tahap penggorengan biji kopi. Industri kopi purnama yang terletak di Jalan Purnama Gg. Purnama 2A $\left(0^{\circ} 0.3^{\prime} 12.21^{\prime \prime S} 109^{\circ} 19^{\prime} 38.62^{\prime \prime}\right)$, mengolah $900 \mathrm{~kg}$ biji kopi mentah per hari. Lama penggorengan yaitu selama 90 menit. Penggorengan ini bertujuan untuk mengurangi kadar air karena kadar air yang tinggi dapat menghambat hasil kopi yang lebih baik, selain itu dapat menimbulkan perubahan warna, serta memunculkan aroma.

Selanjutnya, setelah dilakukan biji kopi tersebut digoreng, biji kopi didinginkan. Pendinginan biji kopi ini dilakukan selama 30 menit hingga 1 jam. Pendinginan ini dilakukan dengan menghampar biji kopi yang telah digoreng dengan tujuan agar tidak menyatu satu sama lain. Jika menyatu, maka bagian tengah biji kopi tersebut masih panas, sehingga bisa menjadi gosong. Setelah didinginkan, biji kopi tersebut dimasukkan ke dalam wadah (karung) selama kurang lebih 1-2 hari. Setelah digoreng, kopi tersebut masih ada sisa $\mathrm{CO}_{2}$. Pengemasan ini bertujuan untuk menghilangkan sisa asap $\left(\mathrm{CO}_{2}\right)$ tersebut. 
Setelah dikemas, biji kopi diayak menggunakan saringan. Pengayakan ini bertujuan untuk memisahkan kulit dari kopi tersebut. Setelah diayak, biji kopi siap digiling. Penggilingan ini mengubah biji kopi menjadi bubuk kopi. Hasil penggilingan kopi per hari yaitu sekitar 600$700 \mathrm{~kg}$ dari $900 \mathrm{~kg}$ biji kopi sebelum diolah. Setelah kopi digiling, kemudian dikemas ke dalam wadah untuk di distribusikan ke masyarakat (konsumen).

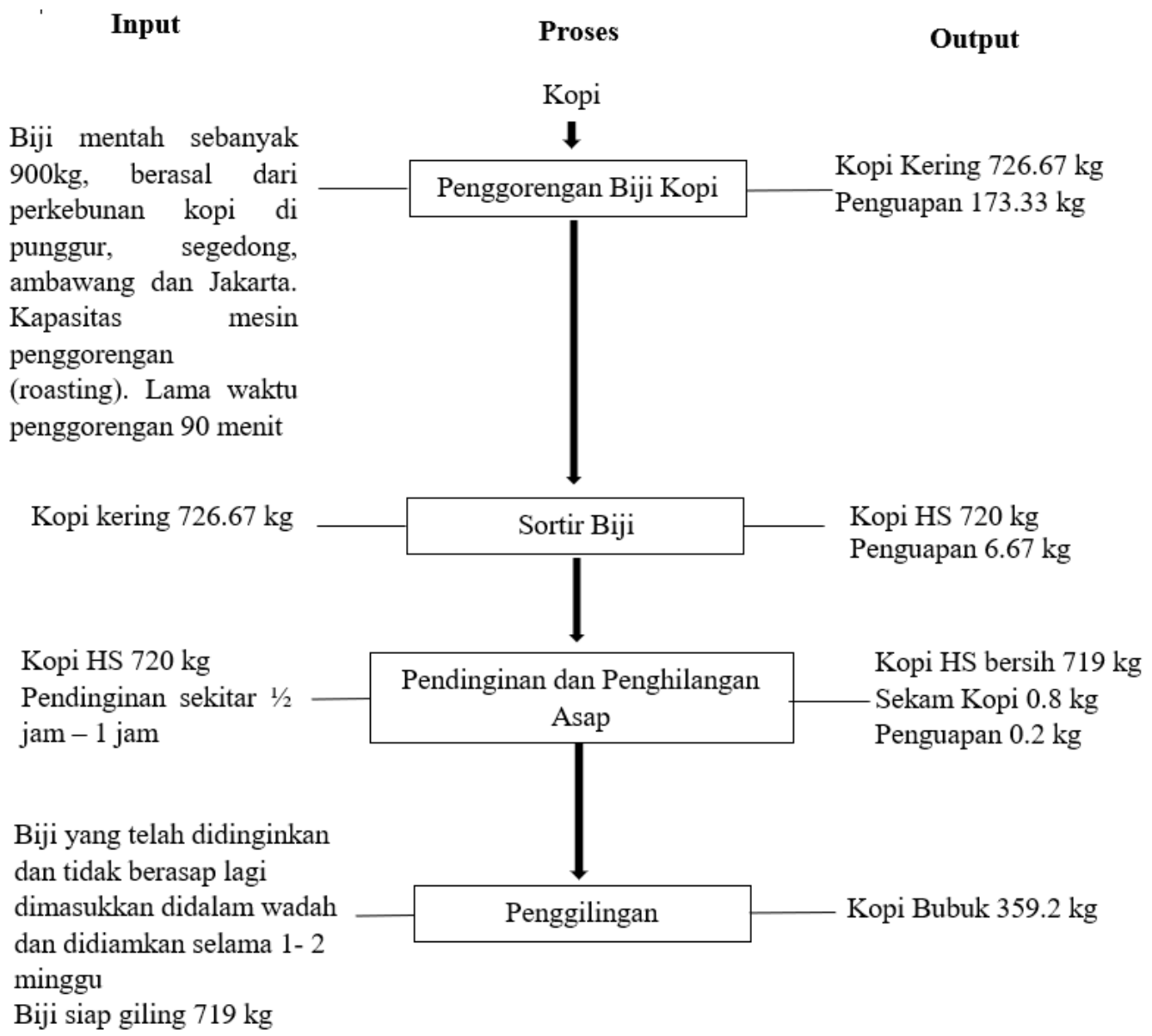

Gambar 1. Diagram Alir Proses Produksi Kopi Purnama per Hari

\section{Produksi Bersih yang Ditawarkan}

Industri Kopi Purnama menghasilkan limbah padat berupa kulit kopi, hal ini dapat menyebabkan adanya pencemaran terhadap lingkungan. Produksi bersih yang ditawarkan adalah pembuatan pupuk bokashi dari sekam kulit kopi. Pupuk Bokashi merupakan pupuk hasil dari fermentasi bahan-bahan organik seperti serubuk gergaji, kotoran hewan, sekam, jerami, dan lain-lain. Dalam penelitian sebelumnya, pembuatan pupuk bokashi ini melibatkan proses fermentasi, yakni saat campuran EM4 dengan sekam kulit kopi didiamkan selama 7 hari, agar proses fermentasinya berjalan dengan baik, maka suhu bahan didalam karung harus berada disekitar $40-50^{\circ} \mathrm{C}$. Jika suhu meningkat, maka perlu membuka karung atau kotak kayu beberapa saat, serta bahan perlu dibolak-balik agar suhu cepat turun. Kemudian, menutup kembali karung/kotak. 


\section{Alat dan Bahan}

Penelitian ini menggunakan karung/kotak papan, cangkul dan gembor sebagai alat. Bahan-bahan yang digunakan terdiri dari sekam kulit kopi, air, gula merah/gula putih dan EM4.

\section{Pembuatan Bioaktivator}



Gambar 2. Diagram Alir Pembuatan Bioaktivator

\section{Pembuatan Pupuk Bokashi dengan Sekam KulitKopi}

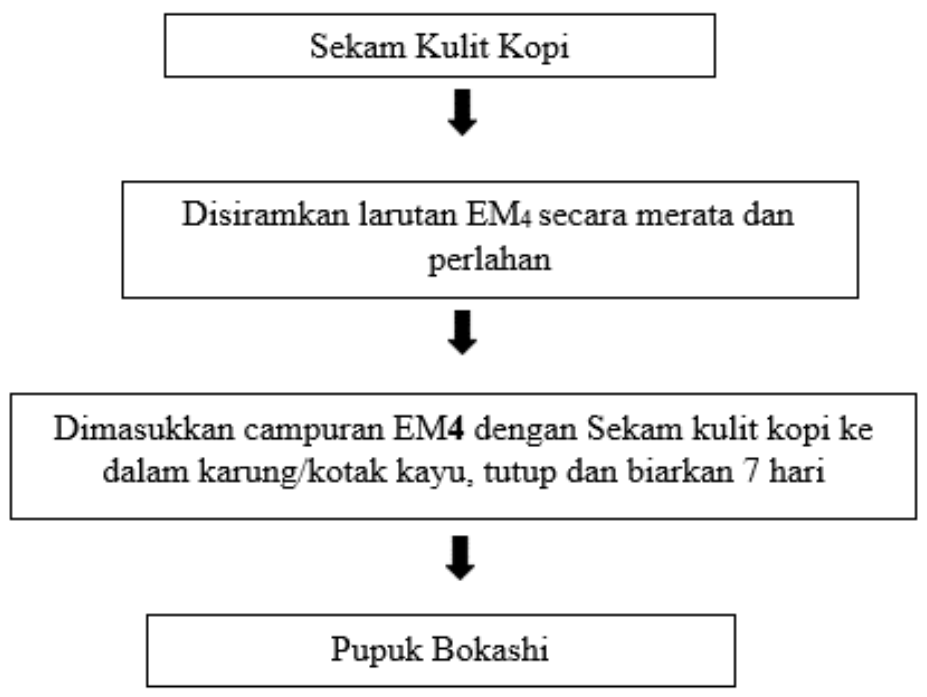

Gambar 3. Diagram Alir Pembuatan Pupuk Bokashi dengan Sekam Kulit Kopi

\section{PENUTUP}

Berdasarkan penelitian yang telah dilakukan, dapat disimpulkan bahwa industri Rumah Kopi Purnama ini menghasilkan limbah padat berupa kulit kopi. Produksi bersih yang ditawarkan adalah pembuatan pupuk bokashi dari sekam kulit kopi. Manfaat produksi bersih bagi lingkungan ini yaitu terjadinya pengurangan timbulan limbah padat di industri tersebut sehingga dapat meminimalisir dampak dari adanya limbah kopi tersebut terhadap lingkungan untuk ke arah industri kopi yang lebih memenuhi standar kualitas lingkungan. 


\section{UCAPAN TERIMA KASIH}

Kami mengucapkan terima kasih kepada seluruh pihak yang terlibat dalam penelitian ini, antara lain kepada dosen pembimbing kami yaitu Ibu Dian Rahayu Jati, S.T., M.Si dan Ibu Isna Apriani, S.T., M.Si yang telah mendukung jalannnya penelitian ini dan juga pihak Industri Rumah Kopi Purnama yang bersedia memberikan izin serta meluangkan waktu untuk ikut terlibat dalam proses penulisan ini

\section{DAFTAR PUSTAKA}

Azizah, Siti Nur, Elida Novita, dan Dian Purbasari. 2019. Potensi Penerapan Produksi Bersih Pada Proses Pengolahan Kopi Arabika Di Agroindustri Maju Mapan Desa Kemiri Kecamatan Panti Kabupaten Jember. Agropross, National Conference Proceedings of Agriculture. Jember

Badan Pengendalian Dampak Lingkungan (BAPEDAL). 1997. Produksi Bersih di Indonesia. Jakarta.

Cahyani, Sri Susanti. 2003. Pengaruh Pemberian Bokashi Terhadap Sifat Fisik dan Mekanik Tanah serta Pertumbuhan Tanaman Pak Choi (Brassica chinensis L). Skripsi. IPBRepository

Clifford,M.NandK.C.Willson.1985.CoffeeBotany,Biochemistry, andProductionofBea ns and Beverage. Croom Helm.London

Erwiyono R, Nurkholis, Baon JB. 2001. Laju Perombakan Kulit Buah Kopi, Jerami Dan Cacahan Kayu Dengan Perlakuan Mikroorganisme Dan Kualitas Kompos Yang Dihasilkan. Pelita Perkebunan 2001. 17(2): 64-71

Fisdiana, Usken dan Eka Mahmud Fitriyadi. 2018. Pengaruh Lama Penyangraian Terhadap

KadarAir,RendemendanWarnaBijiKopiRobusta(Coffeacanephoravar.robusta ex Frochner). UJember

Ganmaa, D., Willett. W.C., Li, T.Y., et al, 2008. Coffee, Tes, Caffein and Rial of Breast Cancer: A 22-year Follow Up. International Journal of Cancer. London

Heuman, J. 1994. Coffee quality, a search for definition. Tea and Coffee Trade Journal. 19 Februari2011

Indrasti, N.S dan Fauzi,A.M. 2009. Produksi Bersih. IPB Press. Bogor

Leroy, T., F. Ribeyre, B. Bertrand, P. Charmetant, M. Dufour, C. Montagnon, P.Marraccini and D. Pot. 2006. Genetics of coffee quality. Mini Review. Brazilian J. Plant Physiol. 18(1): 299-242.

Lia, F. dan Perdana, T. 2017. Sistem Produksi Agroindustri Kopi Arabika (Studi Kasus PT. Sinar Mayang Lestari, Kecamatan Pangalengan, Kabupaten Bandung). Jurnal Agrisep 16 (02) : 123-132.

Mulato, S. Widyotomo, S. Suharyanto, E. 2006. Pengolahan Produk Primer dan Sekunder Kopi. Jember : Pusat Penelitian Kopi dan Kakao Indonesia.

Murtafiah, A. 2012. Daya hambat ekstrak biji kopi robusta (coffea robusta) terhadap streptococcus mutans. Skripsi.

Rahardjo, Pudji. 2012. Panduan Budidaya dan Pengolahan Kopi Arabika dan Robusta. 
Penebar Swadaya. Jakarta

Rahayoe, S., J. Lumbanbatu, dan W. K. J. Nugroho. 2009. Pengaruh Suhu dan Lama Penyangraian terhadap Sifat Fisik-Mekanis Biji Kopi Robusta. Jurnal Penelitian. UGM. Yogyakarta

Salazar-Martinez, E., Willett, W.C., Ascherio, A., Manson, J.E., Leitzmann, M.F., Stampfer, M.J., Hu, F.B. 2004. Coffee Consumption and Risk for Type 2 Diabetes Mellitus. AnnIntern Med. 140(1):1-8.

Simanihuruk, Kiston, dan J. Sirait. 2010. Silase Kulit Buah Kopi Sebagai Pakan Dasar pada Kambing Boerka Sedang Tumbuh. Seminar Nasional Teknologi Peternakan dan Veteriner 2010.

Siringoringo,Freddy.2012.StudiPembuatanTehDaunKopi.Skripsi.DepartemenTeknol ogi Pertanian Fakultas Pertanian USU.Medan.

Susilawati, Rini. 2000. Penggunaan Media Kompos Fermentasi (Bokashi) dan Pemberian Effective Microorganism - 4 (EM-4) Pada Tanah Podzolik Merah Kuning Terhadap Pertumbuhan Semai Acacia mangium Wild. Skripsi. IPB Repository

Villanueva, D., Luna, P., Manic, M., Najdanovic- Visak, V. and Fornari, T., 2011. Extraction of Caffeine from Green Coffee Beans Using Ethyl Lactate. Food Processing, 1, p.3.

Widyotomo, S. (2012). Pasca Panen Kopi. Pusat Penelitian Kopi dan Kakao Indonesia. Jember

Yusmarini. 2011. Mini Review Senyawa Polifenol Pada Kopi, Pengaruh Pengolahan Metabolisme dan Hubungannya dengan Kesehatan Sagu. Vol.10 (2) :22-30

Yusuf, Yuslita. 2000. Pengaruh Pemberian Bokashi Batang Jagung Terhadap Kelengketan Tanah (Soil Stickiness) Pada Alat Pengolahan Tanah Bajak Singkal. Skripsi. IPBRepository

Zainuddin, D. dan T. Murtisari. 1995. Penggunaan Limbah Kopi Agroindustri Buah Kopi (Kulit Buah Kopi) dalam Ransum Ayam Pedaging (Broiler). Puslitbang Peternakan. Bogor. 